AperTO - Archivio Istituzionale Open Access dell'Università di Torino

\title{
Antibacterial coating on polymer for space application
}

\section{This is the author's manuscript}

Original Citation:

Availability:

This version is available http://hdl.handle.net/2318/122569

since 2016-08-26T11:44:29Z

Published version:

DOI:10.1016/j.matchemphys.2012.05.049

Terms of use:

Open Access

Anyone can freely access the full text of works made available as "Open Access". Works made available under a Creative Commons license can be used according to the terms and conditions of said license. Use of all other works requires consent of the right holder (author or publisher) if not exempted from copyright protection by the applicable law. 
This Accepted Author Manuscript (AAM) is copyrighted and published by Elsevier. It is posted here by agreement between Elsevier and the University of Turin. Changes resulting from the publishing process - such as editing, corrections, structural formatting, and other quality control mechanisms - may not be reflected in this version of the text. The definitive version of the text was subsequently published in MATERIALS CHEMISTRY AND PHYSICS, 135, 2012, 10.1016/j.matchemphys.2012.05.049.

You may download, copy and otherwise use the AAM for non-commercial purposes provided that your license is limited by the following restrictions:

(1) You may use this AAM for non-commercial purposes only under the terms of the CC-BY-NC-ND license.

(2) The integrity of the work and identification of the author, copyright owner, and publisher must be preserved in any copy.

(3) You must attribute this AAM in the following format: Creative Commons BY-NC-ND license (http://creativecommons.org/licenses/by-nc-nd/4.0/deed.en), 10.1016/j.matchemphys.2012.05.049

The publisher's version is available at:

http://linkinghub.elsevier.com/retrieve/pii/S0254058412005093

When citing, please refer to the published version.

Link to this full text:

http://hdl.handle.net/2318/122569 


\title{
Antibacterial coating on polymer for space application
}

\author{
Cristina Balagna, $^{\mathrm{a}, *}$, Sergio Perero ${ }^{\mathrm{a}}$, Sara Ferraris ${ }^{\mathrm{a}}$, Marta Miola ${ }^{\mathrm{a}}$, Giacomo Fucale ${ }^{\mathrm{b}}$, Chiara \\ Manfredotti $^{c}$, Alfio Battiato $^{c}$, Daniela Santella $^{\mathrm{d}}$, Enrica Vernè $^{\mathrm{a}}$, Ettore Vittone $^{\mathrm{c}}$, Monica Ferraris $^{\mathrm{a}}$ \\ ${ }^{a}$ Materials Science and Chemical Engineering Department, Politecnico di Torino, Corso Duca \\ degli Abruzzi 24,10129 Torino, Italy \\ ${ }^{b}$ Chemical, Clinical and Microbiological Analyses Department C.T.O., Via G. Zuretti 29, 10126 \\ Torino, Italy \\ ${ }^{c}$ Experimental Physics Department / Centre of Excellence "Nanostructured Interfaces and \\ Surfaces”, University of Torino, and INFN sez.Torino Via P. Giuria 1, 10125 Torino, Italy \\ ${ }^{d}$ Thales Alenia Space - Italia, Space Infrastructures \& Transportation, Engineering - Advanced \\ Projects Unit, Strada Antica di Collegno 253,10146 Torino, Italy \\ *Corresponding author: Tel.: +39011 0904668; Fax : +39011 0904699; \\ E-mail address: cristina.balagna@polito.it
}



composite coating was deposited on a commercial polymer Combitherm ${ }^{\circledR}$, suitable for aerospace application, using the radio frequency (RF) co-sputtering technique. The presence of metallic silver nanocluster and silica were confirmed by energy dispersion spectrometry (EDS), $x$-ray photoelectron spectroscopy (XPS) and localized surface plasmon resonance (LSPR) detected through UV-visible absorption spectrophotometry (UV-Vis). The atomic force microscope (AFM) evidenced the coating morphology. The slight hydrophobicity of both coated and uncoated samples was revealed through the contact angle measurement. The antimicrobial behavior was verified through evaluation of the inhibition halo against several bacterial and fungal species. The coating enhanced the Combitherm ${ }^{\circledR}$ nano-hardness and its resistance to tensile and perforation tests; the coating wear resistance was measured by abrasion test against Kevlar. A folding procedure on the coated Combitherm ${ }^{\circledR}$ and storage in air for three months was also carried out without deterioration of the measured properties. The coating deposition did not influence the air permeability of Combitherm ${ }^{\circledR}$.

Keywords: composite materials, coatings, sputtering, polymers 


\section{Introduction}

The problem of microbiological contamination on board of spacecraft and orbital stations arises from the necessity to prolong space explorations ensuring crewmembers' health, safety and wellbeing, together with the integrity of the spatial structures for the whole duration of the mission [1, 2]. The interior of a space structure can be easily colonized by microorganisms due to the presence of humans and conditions such as humidity and temperature create a suitable environment for the growth of bacteria and fungi [3, 4], able to induce adverse effects as infections, allergies, degradation of air and water $[1,2]$. It was observed that the largest quantity of bacteria and fungi is concentrated on the surfaces of the space structure, in potable water and air [5, 6].

In addition, the increased application of polymers in space and aviations focused the attention of the researchers towards the materials deterioration and degradation. Recently, an inflatable habitat structure was developed and introduced by United States National Aeronautics and Space Administration (NASA, Johnson Space Center) with the function of a high volume module [7]. The inflatable module is composed mainly by a series of polymeric layers, packaged around a central metallic core. This peculiar structure allows the reduction of the initial volume during the launch and the increment of it on orbit, and it must be characterized by several performing functions as the gas retention, structural restraint, material and orbital debris protection, thermal and radiation protection [7, 8]. It is well known that polymers and metals are susceptible to the colonization of microbes and fungi spores, able to quickly develop a microbial biofilm, thanks to the suitable environmental conditions of incubation. The presence of bacteria and the formation of microbial biofilm lead not only to pathogenic effects on humans, but also to the damage and deteriorations of the materials $[4,9]$. The regular cleaning and a controlled inspection and monitoring of the hygiene of the internal structure seem to be not sufficient for avoiding the contamination.

For this purpose, the idea developed in this paper was the deposition of an antibacterial coating on a commercial polymer called Combitherm ${ }^{\circledR}$, commonly used for the food packaging industry, but introduced in space applications, for the realization of the inner part of the inflatable module in contact with crewmembers [8]. The coating has a composite microstructure made of silver nanocluster embedded in a silica matrix. Silver as antimicrobial agent is currently exploited in a wide range of applications where the risk of a bacterial contamination is an issue as in biomedical applications or in crowded places $[9,10]$. The antibacterial property of silver could be expressed from different forms (metallic, nanoparticles and ions) as a coating or incorporated element [14]. Several techniques as sputtering, ions-exchange, sol-gel method, are well studied in literature and available in order to find the suitable method to provide and tailor an antibacterial activity to glasses, ceramics, metals and polymers, considering the requests of the application field [14-23]. 
The authors research group is active in preparation and characterization of materials for

antibacterial applications. Silver ions have been introduced, by means of a patented ion exchange technique [24], onto the surface of bioactive glasses and glass ceramics in bulk form [25, 26], as coatings [27,28] and also in the form of 3D macroporous scaffolds [29, 30].

A detailed characterization of antibacterial silver nanocluster silica composites coatings, prepared by RF co-sputtering deposition technique on silica substrates has been published in [31, 32]. In this paper, silver nanocluster silica composite coating was deposited through the same procedure of RF co-sputtering deposition as in [31-33] on the Combitherm ${ }^{\circledR}$ polymeric substrate, i.e. a multilayer symmetrical film composed of polyethylene, nylon and ethylene vinyl alcohol.

The chemical properties and composition of the antibacterial coating and polymeric substrate were investigated through electron energy dispersion spectrometry (EDS), x-ray photoelectron spectroscopy (XPS) and UV-visible absorption spectrophotometry (UV-Vis). The surface morphology and wettability of the coated sample surface were also reported. The antimicrobial behavior was analyzed through the evaluation of the inhibition halo against several bacterial and fungal species, discovered into the space station of long term missions as Mir Station and International Space Station (IIS) [4, 5]. A series of mechanical tests were performed in order to check the effect of the antibacterial coating on the mechanical properties of the polymeric substrate. The permeability of the film was investigated using air as gas. Finally, the effect of time on the coating properties (antibacterial behavior, adhesion, wettability, hardness and permeability) was investigated on samples stocked in air for three months.

\section{Materials and methods}

\subsection{Coating deposition}

Silver nanocluster silica composite coating was deposited on a commercial polymer (Combitherm ${ }^{\circledR}$ TC XX, Wipak Walsrode GmbH) by RF co-sputtering (Microcoat MS450). The asreceived polymer (AR-Combi, in the text) was a coextruded symmetrical film (140 $\mu \mathrm{m}$ of thickness) made of polyamide with EVOH barrier plus exterior and interior polyethylene layer. Moreover, the surface was treated to provide anti - sticking properties.

The targets used for the deposition were silver (Sigma-Aldrich 99.99\% purity) and silica (Franco Corradi S.r.l. 99.9\% purity). The co-deposition process consisted of applying $200 \mathrm{~W}$ (RF) to a 6 inches silica target, and $1 \mathrm{~W}$ (in pulsed DC mode) to a 1 inch silver target for 15 minutes. The pressure before deposition was $70 \mu \mathrm{Pa}$, while the operating pressure was $5.5 \mathrm{dPa}$. 
This procedure was set after a series of tests in order to avoid the substrate deterioration due to the temperature reached in the sputtering chamber. The coating deposited on the polymer (Combi$C O A T$, in the text) with the optimized parameters had a thickness of about $60 \mathrm{~nm}$.

\subsection{Coating characterization}

The composition of the coating was detected by means of EDS (SEM-FEI, Quanta Inspect 200, EDS - EDAX PV 9900), performed on three different areas of the sample under a voltage of $15 \mathrm{kV}$, and by means of XPS using a VSW TA10 non-monochromatic Al Ka (1486.6 eV) x-ray source equipped with a class 100 concentric hemispherical analyzer.

Furthermore, the Ag nanoclusters embedded in the coating were characterized by means of UV-Vis (Varian Cary 300 Bio) in order to measure their localized surface plasmon resonance (LSPR), an important feature to verify the metallic nature and nano-dimension of silver .

The surfaces of the samples, before and after deposition, were investigated in terms of roughness and wettability. The roughness was estimated through a non-contact atomic force microscopy (AFM, XE-100 with XEI 1.8.0 software) on several sample areas (1x1, 2x2 and 4x4 $\mu \mathrm{m}^{2}$ ). The surface wettability was analyzed through the contact angle measurement, depositing a distilled water drop on the sample surface and elaborating the results using the Expert System Solutions instrument with the assistance of two softwares, Misura ${ }^{\circledR} 3^{\mathrm{HSM}}$ and ImageJ . The test was performed three times for each sample.

\subsection{Antibacterial behavior}

The antibacterial behavior of the silver nano-cluster silica composite coating was verified through the inhibition zone evaluation towards several bacteria, Gram positive (Staphylococcus aureus, Bacillus cereus) and Gram negative (Morganella, Klebsiella pneumonite, Escherichia coli) and fungal species (Candida parapsilosis, Candida albicans, Candida glabrata) in accordance to standards of the National Committee for Clinical Laboratory (NCCLS) [34], as described in previous work [31]. Some of these species were identified on board of International Space Station and Mir station [4, 5].

\subsection{Mechanical tests}

A series of mechanical tests were carried out in order to control the effect of the co-sputtering deposition on the properties of the polymeric film.

The adhesion of the coating to the substrate was evaluated through a tape test according to the ASTM D3359 - 97 standard [35]. A grid of parallel lines was made by a cutter on the sample 
surface, and then, cleaned by a brush. Afterwards the tape was attached to the grid, then removing, the surface was finally observed with a lens for detecting coating damage.

The nano-hardness of the samples was determined through a nano-indentation test using a suitable platform instrument (NanoTest ${ }^{\mathrm{TM}}$ ). The test was performed with several indentations on each sample, using a Berkovic tip, under different applied loads (1, 0.5 and $0.1 \mathrm{mN}$ ) and an indentation rate of $0.002 \mu \mathrm{m} / \mathrm{s}$. The nano-indentation measurement is an important and suitable method for analyzing the mechanical response of thin coating and films towards an applied load [36]. The data obtained from the instrument are the indentation depth, the hardness and the reduced modulus which is directly correlated to the Young's modulus of the tested material, considering the contribution of the indenter material properties (elastic modulus and Poisson's ratio).

The resistance to tensile, tear, perforation and abrasion was evaluated following the respective UNI 8279-4:1984, UNI 9073-4:1999, UNI 5421:1983 and UNI 12947-2:2000 standards referred to fabric and woven [37-40]. The AR-Combi samples were cut and then subjected to the deposition of the silver nano-cluster silica composite coating. A coated sample subjected to a folding procedure (Combi-COAT-F, in the text) was also tested. This folding procedure was carried out creasing the coated film by hand, five times, obtaining random pleats. The folded material was useful to simulate the final condition of polymer which has to be packaged for realizing the inflatable modulus. The dimensions and the number of samples for each test are summarized in Table 1.

In the case of the tensile test, the standard dimensions were too large with respect to the dimensions of the sputtering chamber (a sample with a maximum size of $10 \times 10 \mathrm{~cm}^{2}$ can be sputtered). Hence the polymer was evaluated with the standard size AR-Combi and with a smaller size (AR-Combismall, in the text) suitable for the sputtering chamber size and having the same size of the coated polymers Combi-COAT for comparison purposes. The ultimate strength $(\mathrm{N})$ was reported for the tensile, tear and perforation tests. In addition, the tensile percentage elongation was measured.

The abrasion test was performed for 50000 cycles and it was stopped after a defined number of cycles in order to control the conditions of the deposited coating. Kevlar was used as abrasive counterpart material (instead of the standard wool) because in the real application of the inflatable modulus the inner part is a sequence composed of three Combitherm ${ }^{\circledR}$ films separated by Kevlar layers.

\subsection{Gas permeability}

The permeability to the air of the AR-Combi, to Combi-COAT and the Combi-COAT-F was obtained using a semi-quantitative method by means a permeometer (Lyssy L100-5000). The instrument measures the pressure difference between the chambers above and below the sample and 
the obtained value is converted to transmission rate $\left(\mathrm{TR}, \mathrm{ml} /\left(\mathrm{m}^{2} *\right.\right.$ day $\left.)\right)$. The test was performed three times for each sample at $23^{\circ} \mathrm{C}$. The permeability, expressed by $\mathrm{ml} * \mathrm{~mm} /\left(\mathrm{m}^{2} *\right.$ day*atm $)$, could be obtained by means of the equation below:

(1)

$$
\text { Permeability }=\frac{T R^{*} T}{\Delta P}
$$

where $\mathrm{T}$ is the thickness of the film $(\mathrm{mm}), \Delta \mathrm{P}$ is the pressure difference between the chambers (about $1 \mathrm{~atm}$ ).

\subsection{Air-ageing}

The Combi-COAT samples were stocked in a laboratory environment in air at room temperature for $7,14,28,84$ days. The aged samples were labeled adding the suffix "-number of days- $d$ " to the name Combi-COAT (e.g. Comb-COAT-7d). Properties of the aged samples, i.e. the composition, wettability and adhesion of the coating, nano-hardness, permeability and antibacterial behavior were analyzed and compared with the pristine coated sample.

\section{Results and discussions}

\subsection{Coating deposition through co-sputtering}

A co-sputtering time (15 minutes) was chosen for the deposition of the silver nano-cluster silica composite layer with a thickness of $60 \mathrm{~nm}$ on the Combitherm ${ }^{\circledR}$ polymer substrate. It was observed in preliminary tests that a longer sputtering time deteriorates the polymer substrate.

\subsection{Coating characterization}

The EDS analysis of the silver nanocluster-silica composite layer, shown in Fig. 1, confirms the presence of elemental $\mathrm{Si}$ and $\mathrm{Ag}$, belonging to the deposited layer. The two peaks of the $\mathrm{Si}$ and $\mathrm{Ag}$ are visible on the EDS spectrum. The carbon and oxygen derive from the polymer substrate.

A more detailed surface analysis has been carried out by XPS as shown in Fig. 2 for the ARCombi and the Combi-COAT. Only the principal core lines of the $\mathrm{O}$ and $\mathrm{C}$ (polymer hydrocarbon chains) and the corresponding Auger series are detected into the spectrum of the substrate ( Fig. 2a). The spectrum of the Combi-COAT (Fig. 2b) reveals the presence of $\mathrm{Ag}$ at around $368 \mathrm{eV}$ as evaluated with respect to the $\mathrm{C} 1 \mathrm{~s}$ peak at $285 \mathrm{eV}$ : the spectral resolution does not allow a clear discrimination between metallic and ionic $\mathrm{Ag}$ species; the $\mathrm{Ag} / \mathrm{Si}$ ratio is around 25\% . The $\mathrm{Si} 2 \mathrm{p}$ and 
$\mathrm{O}$ 1s peaks are located at binding energies of $104 \mathrm{eV}$ and $533 \mathrm{eV}$, respectively; these values are compatible with pure silica, as confirmed by the $\mathrm{O} / \mathrm{Si}$ ratio which is $(2.0 \pm 0.1)$.

The UV-Vis absorption spectrum of the silver nanocluster silica composite coating (CombiCOAT ) is shown in Fig. 3, as obtained by subtracting the contribution of the polymer substrate. A large absorption feature between 325 and $700 \mathrm{~nm}$ with a maximum at $439 \mathrm{~nm}$ is clearly visible, due to the LSPR of silver metal nanoclusters [41]. The maximum results slightly shifted with respect to the LSPR peak $(414 \mathrm{~nm})$ measured for the silver nanoclusters silica composite layer deposited on the silica substrate, analyzed in the previous work [31]. However, it is worth noticing that the deposition process in this work has been carried out with different parameters optimized for the polymeric substrate; this influences both the dimensions of the silver nanoclusters (estimated below $20 \mathrm{~nm}$ ) and their mutual interaction, responsible for the broad tail up to $700 \mathrm{~nm}$.

The morphology of the AR-Combi and Combi-COAT surfaces were evaluated through AFM as shown in Fig. 4. The AFM maps of the uncoated polymer revealed a slight increase of the root mean squared roughness $(\mathrm{Rq})$ as function of the analyzed map area (not reported). At the smallest area $\left(1 \mathrm{x} 1 \mu \mathrm{m}^{2}\right)$, the map shows a honeycomb structure typical of polymers (Fig. 4a) and a Rq of about $10 \mathrm{~nm}$. Similarly, the Combi-COAT samples show an increase of the Rq as function of the map area. At the largest scale the high value of $\mathrm{Rq}$ (about $30 \mathrm{~nm}$ ) can be due to an enhanced wrinkling of the surface induced by the sputtering process. At the smallest scale, although the RMS value is very close to the uncoated one, the honeycomb structure of the substrate disappears and the nano-structured nature of the deposited silver doped silica thin film is clearly evident, as shown in Fig. $4 b$.

The slight hydrophobicity of the AR-Combi formed a contact angle of about $74^{\circ}$ which remained unvaried also on all the coated samples (Combi-COAT) before and after ageing .

\subsection{Antibacterial activity}

The antibacterial activity of the Combi-COAT and the aged Combi-COAT samples towards several bacterial species, both Gram positive (S. aureus, Bacillus cereus) and Gram negative (Morganella, K. pneumoniae ed E. coli), was evaluated through the inhibition halo test and the results are reported in the Fig. 5. The Combi-COAT samples are able to develop an inhibition zone whose dimensions and morphology depend to the sensitivity of the bacterial strain. In particular, the silver affects significantly the Escherichia coli and the Bacillus cereus species, forming a 2-3 mm halo on the agar. A smaller halo of about $1 \mathrm{~mm}$ was observed for S. aureus and Morganella species, this behavior can be attributed to the different structure of cell wall as reported in literature [42]. Some samples did not completely adhere to the agar surface, thus giving the formation of non 
uniform halo. Finally, the gradual and not well-defined halo in the case of the Klebsiella indicates that the release of silver stops the bacteria growth and proliferation only very close to the samples. The antibacterial behavior of the samples remains almost unchanged after 28 days of air-ageing: just a slightly decrease of antimicrobial effect for the Combi-COAT84d was observed, in particular towards the E. coli and Bacillus cereus strains.

Fig. 6 reports the results of contact test against several Candida species. All the samples developed a relevant antimicrobial effect with the formation of a halo with dimensions of about 2$3 \mathrm{~mm}$ also after 28 days of ageing in air. On the contrary, the fungi proliferation was stopped under the Combi-COAT84d samples, but the material was not able to produce a visible halo around it.

\subsection{Mechanical tests}

A series of tests were performed in order to study the mechanical behavior of the AR-Combi substrate before and after the silver nanocluster silica composite coating.

The as deposited coating resulted well adherent to the polymer, as reported in Fig. 7: the tape test (ASTM D3359 - 97 standard [35]) did not induce any detectable damage on the coated sample (Fig. 7a) and no sign of the coating detachment was visible on the tape (not reported). The effect of ageing did not influence the adhesion coating-substrate (Fig. 7b-e). Hence, the samples could be classified as $5 \mathrm{~B}$ with $0 \%$ of damage according to the corresponding standard [35].

The nano-hardness of all the samples was tested through several nano-indentations at different maximum loads in order to investigate the nano-mechanical behavior of the substrate and the coating-substrate system. The graphic comparison of the depth-load curves between AR-Combi and Combi-COAT for each applied load is reported in Fig. 8. As it could be observed, the curves of the Combi-COAT samples are significantly shifted with respect to the untreated substrates for all the applied loads (Fig. 8b-d), indicating an increment of the hardness and stiffness of the coated material. The indenter overlapped the coating and it penetrated into the polymeric film, but it reached a lower depth in the coated samples than in the substrate. The analysis of the curves and the average values in terms of the indentation depth, nano-hardness and reduced modulus reported in Table 2, confirm the improvement of the nano-mechanical properties of the coated samples. The increment of load determined an increment of the indentation depth and a decrement in the registered hardness and reduced modulus. The hardness and the reduced modulus of the CombiCOAT varied from 171 until $47 \mathrm{MPa}$ and 1.2 until $0.6 \mathrm{GPa}$, respectively, in contrast with the hardness and the modulus of the AR-Combi which are only 49 until $28 \mathrm{MPa}$ and 0.6 until $0.4 \mathrm{GPa}$, respectively. 
The air ageing did not affect the nano-mechanical behaviour of the samples and the depth-load curves (not reported) remained unchanged with respect to the Comb-COAT for all the evaluated samples.

The tensile, tear and perforation properties were evaluated through the tests according to the UNI 8279-4:1984, UNI 9073-4:1999 and UNI 5421:1983 standards for woven and fabric materials [35-37] and the results are summarized in Table 3.

The tensile and perforation resistance seem to be positively influenced by the presence of the silver nanocluster silica composite coating. The AR-Combi with the standard dimensions $(100 \times 150 \mathrm{~mm})$ has a tensile strength of about $172 \mathrm{~N}$ reaching an elongation of about $26 \%$ and the reduction of the dimensions of the sample (AR-Combi-small) resulted in a decrement of the maximum strength $(149 \mathrm{~N})$ with a negligible increment of the elongation, within the standard deviation. The coated materials demonstrated a very good behavior with a significant increment of the tensile resistance and an higher elongation with respect to the corresponding uncoated small material, probably due to a structural modification of the polymer chains after sputtering. The perforation resistance increased with the presence of the coating and this result confirms the improvement of the polymer surface mechanical properties, after coating. The tear resistance is unaffected by the coating deposition.

In the abrasion test (UNI 12947-2:2000 standard [38]), all the samples resisted until 50000 cycles in contact with the Kevlar fabric without the fracture of the polymeric substrates. It is possible to define three steps during the whole test, related to the coating behavior. Initially (100500 cycles), the coating was removed at the edge of the sample. Then, the deposited layer was partially removed between 500 and 3000 cycles and the surface appeared with dark and light spot. Finally, the coating was completely removed from the polymeric substrate between 3000 and 5000 cycles.

\subsection{Permeability tests}

The permeability tests were performed on pure substrate and on the coated polymer before and after folding and air ageing. Results on transmission rate (TR) and the permeability (P) for $140 \mu \mathrm{m}$ thick samples were obtained as average values of three measurements per sample as in Fig. 9. No relevant differences were measured between coated and uncoated polymer and the transmission rate and the permeability were about $14 \mathrm{ml} / \mathrm{m}^{2} *$ day and $2 \mathrm{ml} * \mathrm{~mm} / \mathrm{m}^{2} *$ day*atm, respectively. 
The presence of pleats on the polymeric film due to the folding procedure increases the values of transmission rate and permeability probably because the sample was not completely flat, with several air gaps on the surface which influence the measure.

After ageing, the transmission rate and permeability to air of the samples increased but they reached values which could be considered in the impermeability range. Hence, it is possible to affirm that the coating did not significantly change the air impermeability of the starting polymer.

\section{Conclusions}

In conclusion, a silver nanocluster silica composite coating was deposited on a commercial polymeric film, called Combitherm ${ }^{\circledR}$, currently proposed as a new material in the aerospace field, thanks to its peculiar characteristic of air impermeability. The coating had a thickness of about 60 $\mathrm{nm}$ and it was deposited on the substrate by means of magnetron RF-DC pulsed co-sputtering of silica and silver targets, with an optimized process time of 15 minutes. The optimized sputtering parameters avoided the damage and deterioration of the polymeric substrate.

The composition of the coating was confirmed by EDS and XPS analysis and the silver nanoclusters presence of the silica matrix was also evidenced by measuring the SPR peak.

The morphological analysis carried out by AFM on scales of $1 \mu \mathrm{m}^{2}$ evidences the nanostructure of the silver doped silica thin film.

The slight hydrophobicity of the substrate was maintained after the coating deposition.

The antibacterial effect of the silver nanocluster silica composite coating was demonstrated against different bacteria and fungi strains by the formation of an inhibition halo or by the absence of micro-organisms growth under the samples also after 84 days of air-ageing .

The coating resulted well adherent to the substrate and it is completely removed only after 3000 - 5000 cycles of abrasion against a Kevlar fabric. In addition, the coating improved the nanomechanical behavior and the resistance to tensile and perforation tests but it did not significantly influence the tear resistance. The folding procedure and the air ageing did not significantly influence the properties of the substrate and of the silver nanoclusters silica composite coating.

The presence of coating did not influence the air permeability of the polymer which remained very low (about $2 \mathrm{ml} * \mathrm{~mm} / \mathrm{m}^{2} *$ day*atm). Even if the ageing increased the permeability of the sample, the values obtained could be considered very low. 


\section{Acknowledgements}

This work was funded by Regione Piemonte, Italy, with the Project "NABLA-Nanostructured Antibacterial Layers".

This research is supported by Thales Alenia Space IT, Space Infrastructures \& Transportation Engineering - Advanced Projects Unit 


\section{References}

[1] D.L.Pierson, Gravit. Space Biol. Bull. 14 (2001) 1-6.

[2] V.K. Ilyin, Acta Astronaut. 56 (2005) 839-850.

[3] J.Gu, Int. Biodeterior. Biodegrad. 59 (2007) 170-179.

[4] R. Klintworth, A.N. Viktorov, D. Bohle, Acta Astronaut. 44 (1999) 569-578.

[5] N. Novikova, P. De Boever, S. Poddubko, E. Deshevaya, N. Polikarpov, N. Rakova, I. Coninx, M. Mergeay, Res. Microbiol. 157 (2006) 5-12.

[6] B. Song, L.G. Leff, Microbiol. Res.160 (2005) 111-117.

[7] D. Cadogan, J. Stein, M. Grahne, Acta Astronaut. 44 (1999) 399-406.

[8] E.J. Brandon, M. Vozoff, E.A. Kolawa, G. F. Studor, F. Lyons, M.W. Keller, B. Beiermann, S.R. White, N.R. Sottos, M.A. Curry, D.L. Banks, R. Brocato, L. Zhou, S. Jung, T.N. Jackson, K. Champaigne, Acta Astronaut. 68 (2011) 883-903.

[9] B.S. Atiyeh, M. Costagliola, S.N. Hayek, S.A. Dibo, Burns 33 (2007) 139-148.

[10] M. Zielecka, E. Bujnowska, B. Kepska, M. Wenda, M. Piotrowska, Prog. Org. Coat. (2011) in press, doi:10.1016/j.porgcoat.2011.01.012.

[11] J.Gu, M. Roman, T. Esselman, R. Mitchell, Int. Biodeterior. Biodegrad. 41 (1998) 25-33.

[12] M.Rai, A. Yadav, A. Gade, Biotechnol. Adv. 27 (2009) 76-83.

[13] D.P. Dowling, K. Donnelly, M.L. McConnell, R. Eloy, M.N. Arnaud, Thin Solid Film 398-399 (2001) 602-606.

[14] N. Masuda, M. Kawashita, T. Kokubo, J. Biomed. Mater. Res. Part B: Appl. Biomater. 83B (1) (2007) 114-120.

[15] R.X. Wang, X.M. Tao, Y. Wang, G. F. Wang, S.M. Shang, Surf. Coat. Technol. 204 (2010) 1206-1210.

[16] S. Di Nunzio, C. Vitale Brovarone, S. Spriano, D. Milanese, E. Vernè, V. Bergo, G. Maina, P. Spinelli, J. Eur. Ceram. Soc. 24 (2004) 2935-2942.

[17] S.B. Sant, K.S. Gill, R.E. Burrell, Acta Biomater. 3 (2007) 341-350.

[18] W. Chen, Y. Liu, H.S. Courtney, M. Bettenga, C.M. Agrawal, J.D. Bumgardner, J.L. Ong, Biomater. 27 (2006) 5512-5517.

[19] D. Chiaretta, D. Milanese, Y. Menke, M. Ferraris, F. Pirri, J. Non Cryst. Solids 352 (2006) 2548-2552.

[20] E. Korner, P. Rupper, J.F. Lubben, A. Ritter, J. Ruhe, D. Hegemann, Surf. Coat. Technol. 205 (2011) 2978-2984.

[21] S.X. Jiang, W.F. Qin, R.H. Guo, L. Zhang, Surf. Coat. Technol. 204 (2010) 3662-3667. 
[22] R.X. Wang, X.M. Tao, Y. Wang, G.F. Wang, S.M. Shang, Surf. Coat. Technol. 204 (2010) 1206-1210.

[23] Q.F. Wei, H. Ye, D. Y. Hou, H.B. Wang, W.D. Gao, J. Appl. Polym. Sci. 99 (2006) 23842388.

[24] S. Di Nunzio, E. Vernè, WO2006/058906 (2006).

[25] S. Di Nunzio, M. Miola, C. Vitale Brovarone, M. Cannas, S. Gatti, G. Fucale, G. Maina, A.

Massé, E. Verné, J. Mater. Sci. Mater. Med. 20 (2009) 733-740.

[26] E. Vernè, S. Ferraris, M. Miola, G. Fucale, G. Maina, G. Martinasso, R.A. Canuto, S. Di

Nunzio, C. Vitale Brovarone, Adv. Appl. Ceram. 107 (2008) 234-244.

[27] M. Miola, S. Ferraris, S. Di Nunzio, P. Robotti, G. Bianchi, G. Fucale, G. Maina, M. Cannas,

S.Gatti, A. Masse, C. Vitale-Brovarone, E. Vernè, J. Mater. Sci. Mater. Med. 20 (2009) 741-749.

[28] E. Vernè, S. Ferraris, M. Miola, G. Fucale, G. Maina, P. Robotti, G. Bianchi,

G. Martinasso, R.A. Canuto, C. Vitale Brovarone, Adv Appl. Ceram. 107 (2008) 245-253.

[29] C. Vitale Brovarone, M. Miola, C. Balagna, E. Vernè, Chem. Eng. J. 137 (2008) 129-136.

[30] C. Balagna, M. Miola, C. Vitale Brovarone, R. A. Canuto, S. Saracino, G. Muzio, G. Fucale, G. Maina, E. Vernè, J. Biomater. Appl. 25 (2011) 595-617.

[31] M. Ferraris, S. Perero, M. Miola, S. Ferraris, E. Vernè, J. Morgiel, Mater. Chem. Phys. 120 (2010) 123-126.

[32] M. Ferraris, S. Perero, M. Miola, S. Ferraris, G. Gautier, G. Maina, G. Fucale, E. Vernè, Adv. Eng. Mater. 12 (2010) B276-B282.

[33] M. Ferraris, D. Chiaretta, M. Fokine, M. Miola, E. Verne', TO2008A000098 (2008).

[34] NCCLS M2-A9 Performance Standards for Antimicrobial Disk Susceptibility Tests, Approved Standard- Ninth Edition (2006).

[35] ASTM D3359 - 97, Standard Test Methods for Measuring Adhesion by Tape Test

[36] D.A. Lucca, K. Herrmann, M.J. Klopfstein, CIRP Ann. - Manuf. Technol. 59 (2010) 803-819.

[37] UNI 8279-4:1984, Nonwovens- Test methods- Determination of tensile strength (Grab Test)

[38] UNI 9073-4:1999, Textiles- Test methods for nonwovens- Determination of tear resistance

[39] UNI 5421:1983, Textiles- Determination of the perforation resistance by the ball method

[40] UNI 12947-2:2000, Textiles- Determination of the abrasion resistance of fabrics by the Martindale method

[41] J. F. Sánchez-Ramírez, U. Pal, L. Nolasco-Hernández, J. Mendoza-Álvarez, J. A. PescadorRojas, J. Nanomater. 2008 (2008) 1-9.

[42] D.R. Monteiro, L.F. Gorup, A.S. Takamiya, A.C. Ruvollo-Filho, E.R. De Camargo, D.B. Barbosa, Inter. J. Antimicrob. Agent 34 (2009) 103-110. 


\section{Figure captions}

Fig. 1. EDS analysis of the AR-Combi-COAT sample

Fig. 2. XPS survey spectra of (a) AR-Combi and (b) Combi-COAT

Fig. 3. UV-Vis spectra of the coating deposited on the polymer (The contribution of the polymer substrate was directly subtracted from the curve because the material was used as background spectrum)

Fig. 4. AFM maps $\left(1 \times 1 \mu \mathrm{m}^{2}\right)$ of the surface of (a) the substrate AR-Combi and (b) the coating Combi-COAT. The Rq values are reported in the vertical axis.

Fig. 5. Inhibition halo test against different bacteria: Combi-COAT and aged Combi-COAT samples

Fig. 6. Inhibition halo tests against different fungi species: Combi-COAT and aged Combi-COAT samples

Fig. 7.Samples surfaces before and after the tape test: Combi-COAT, Combi-COAT-7d, CombiCOAT-14d, Combi-COAT-28d, Combi-COAT-84d

Fig. 8. Comparison of the nanoindentation depth-load curves between AR-Combi and CombiCOAT samples, at the maximum load of (a) $0.03 \mathrm{mN}$, (b) $0.1 \mathrm{mN}$, (c) $0.5 \mathrm{mN}$ and (d) $1 \mathrm{mN}$

Fig. 9. Permeability test: (a) trasmission rate; (b) permeability

Fig. 10. Inhibition halo test against different bacteria: Combi-COAT and aged Combi-COAT samples

Fig. 11. Inhibition halo tests against different fungi species: Combi-COAT and aged Combi-COAT samples 
Table 1: Number and dimensions $(\mathrm{mm})$ of the samples mechanically tested

\begin{tabular}{|c|c|c|c|c|}
\hline Test & AR-Combi & AR-Combi-small & Combi-COAT & Combi-COAT-F \\
\hline $\begin{array}{l}\text { Tensile } \\
\text { (UNI 8279-4:1984) }\end{array}$ & $\begin{array}{c}3 \\
(100 \times 150)\end{array}$ & $\begin{array}{c}3 \\
(100 \times 80)\end{array}$ & $\begin{array}{c}3 \\
(100 \times 80)\end{array}$ & $\begin{array}{c}3 \\
(100 \times 80)\end{array}$ \\
\hline $\begin{array}{l}\text { Tear } \\
\text { (UNI 9073-4:1999) }\end{array}$ & $\begin{array}{c}3 \\
(100 x 45)\end{array}$ & l & $\begin{array}{c}3 \\
(100 x 45)\end{array}$ & $\begin{array}{c}3 \\
(100 x 45)\end{array}$ \\
\hline $\begin{array}{l}\text { Perforation } \\
\text { (UNI 5421:1983) }\end{array}$ & $\begin{array}{c}5 \\
\text { (diameter 50) }\end{array}$ & I & $\begin{array}{c}5 \\
\text { (diameter 50) }\end{array}$ & $\begin{array}{c}5 \\
\text { (diameter 50) }\end{array}$ \\
\hline $\begin{array}{l}\text { Abrasion } \\
\text { (UNI 12947-2:2000) }\end{array}$ & $\begin{array}{c}10 \\
\text { (diameter 40) }\end{array}$ & I & $\begin{array}{c}10 \\
\text { (diameter 40) }\end{array}$ & $\begin{array}{c}10 \\
\text { (diameter 40) }\end{array}$ \\
\hline
\end{tabular}


Table 2: Data from nanoindentation test

\begin{tabular}{clcc}
\hline \multirow{2}{*}{ Load (mN) } & \multicolumn{1}{c}{ Parameters } & \multicolumn{2}{c}{ Samples } \\
\cline { 3 - 4 } & & AR-Combi & Combi-COAT \\
\hline \multirow{2}{*}{$\mathbf{0 . 1}$} & Max depth (nm) & $388 \pm 15$ & $234 \pm 6$ \\
\cline { 2 - 4 } & Hardness (MPa) & $49 \pm 5$ & $171 \pm 14$ \\
\cline { 2 - 4 } & Reduced modulus (GPa) & $0.6 \pm 0.1$ & $1.2 \pm 0.1$ \\
\hline \multirow{2}{*}{$\mathbf{0 . 5}$} & Max depth (nm) & $948 \pm 54$ & $754 \pm 11$ \\
\cline { 2 - 4 } & Hardness (MPa) & $37 \pm 4$ & $59 \pm 2$ \\
\cline { 2 - 4 } $\mathbf{1}$ & Reduced modulus (GPa) & $0.5 \pm 0.1$ & $0.7 \pm 0.02$ \\
\hline & Max depth (nm) & $1498 \pm 72$ & $1185 \pm 10$ \\
\cline { 2 - 4 } & Hardness (MPa) & $28 \pm 2$ & $47 \pm 1$ \\
\cline { 2 - 4 } & Reduced modulus (GPa) & $0.4 \pm 0.05$ & $0.6 \pm 0.03$ \\
& & &
\end{tabular}


Table 3: Mechanical properties of the samples

\begin{tabular}{|c|c|c|c|c|}
\hline \multirow[t]{2}{*}{ Sample } & \multicolumn{2}{|c|}{$\begin{array}{c}\text { Tensile } \\
\text { UNI 8279-4:1984 }\end{array}$} & \multirow{2}{*}{$\begin{array}{c}\text { Tear } \\
\text { UNI 9073-4:1999 } \\
\text { Ultimate strength } \\
(\mathrm{N})\end{array}$} & \multirow{2}{*}{$\begin{array}{c}\text { Perforation } \\
\text { UNI 5421:1983 } \\
\text { Ultimate strength } \\
(\mathrm{N})\end{array}$} \\
\hline & $\begin{array}{l}\text { Ultimate Strength } \\
(\mathrm{N})\end{array}$ & $\begin{array}{c}\text { Elongation } \\
(\%)\end{array}$ & & \\
\hline AR-Combi & $172 \pm 5$ & $26 \pm 2$ & $37 \pm 6$ & $205 \pm 15$ \\
\hline AR-Combi small & $149 \pm 3$ & $30 \pm 7$ & - & - \\
\hline Combi-COAT & $179 \pm 6$ & $42 \pm 7$ & $32 \pm 2$ & $246 \pm 14$ \\
\hline Combi-COAT-F & $180 \pm 4$ & $46 \pm 1$ & $33 \pm 5$ & $245 \pm 9$ \\
\hline
\end{tabular}


Click here to download high resolution image
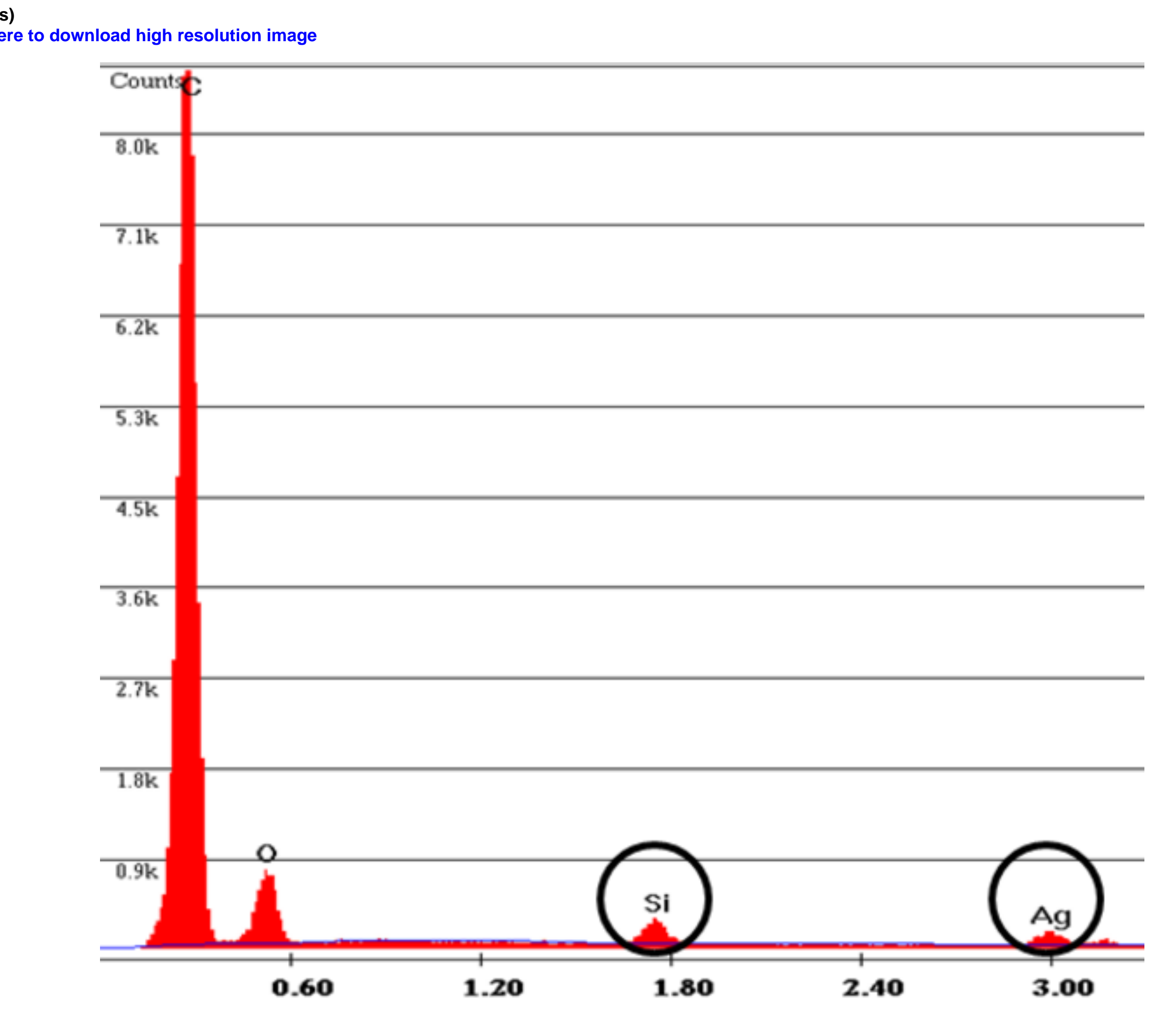
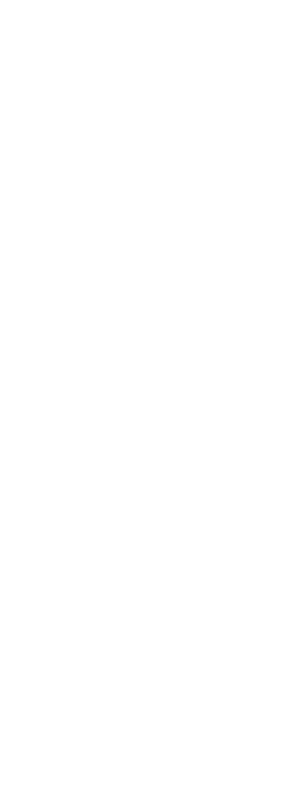
Click here to download high resolution image

(a)

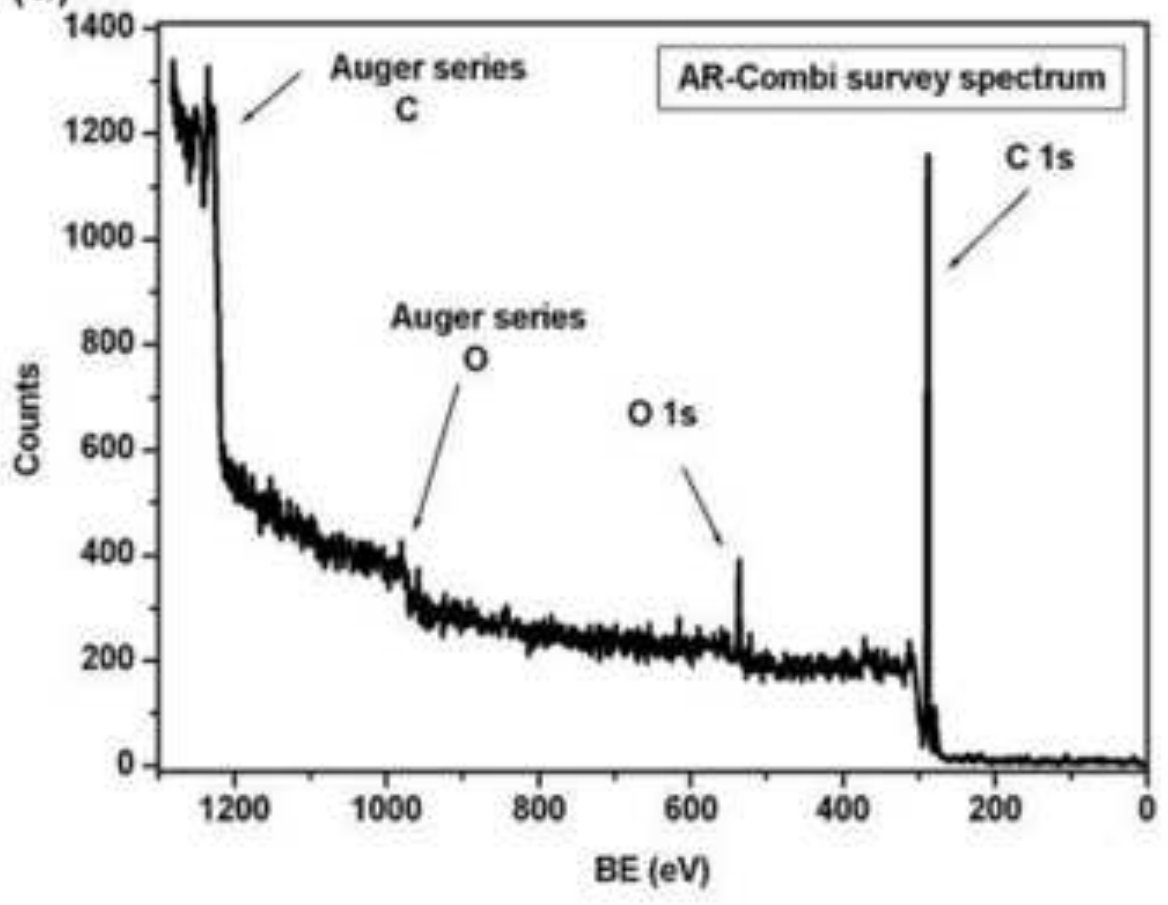

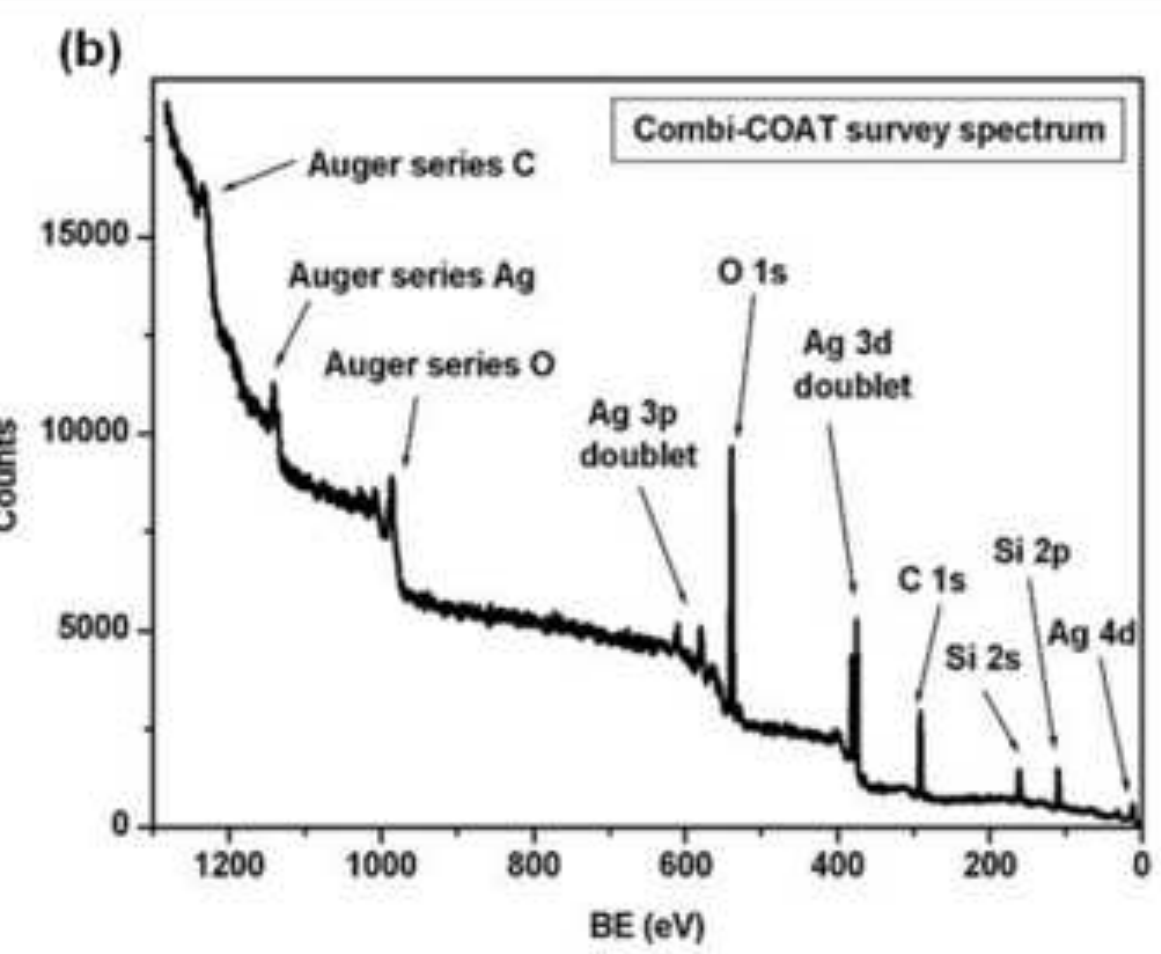


Click here to download high resolution image

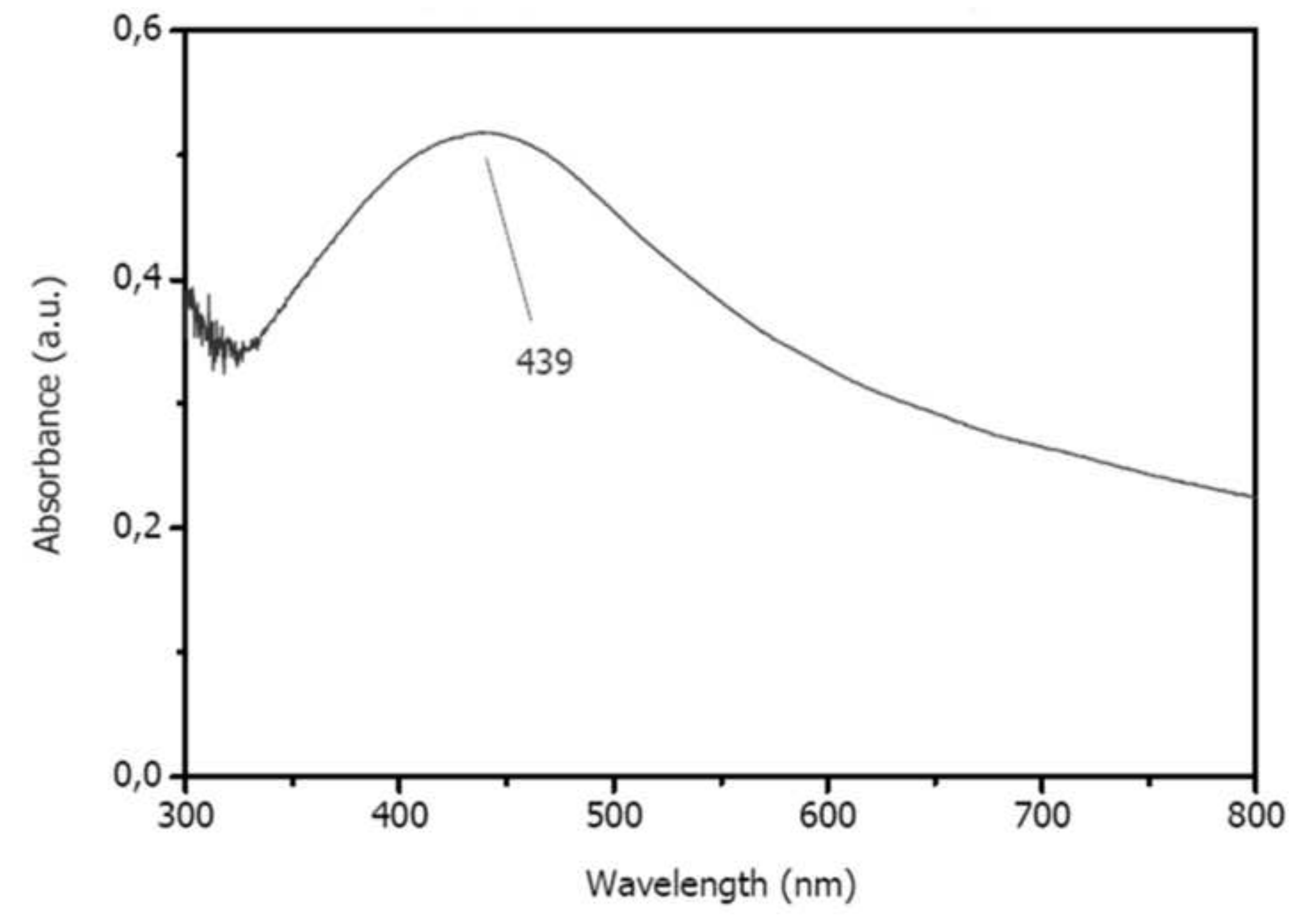


Click here to download high resolution image

(a)

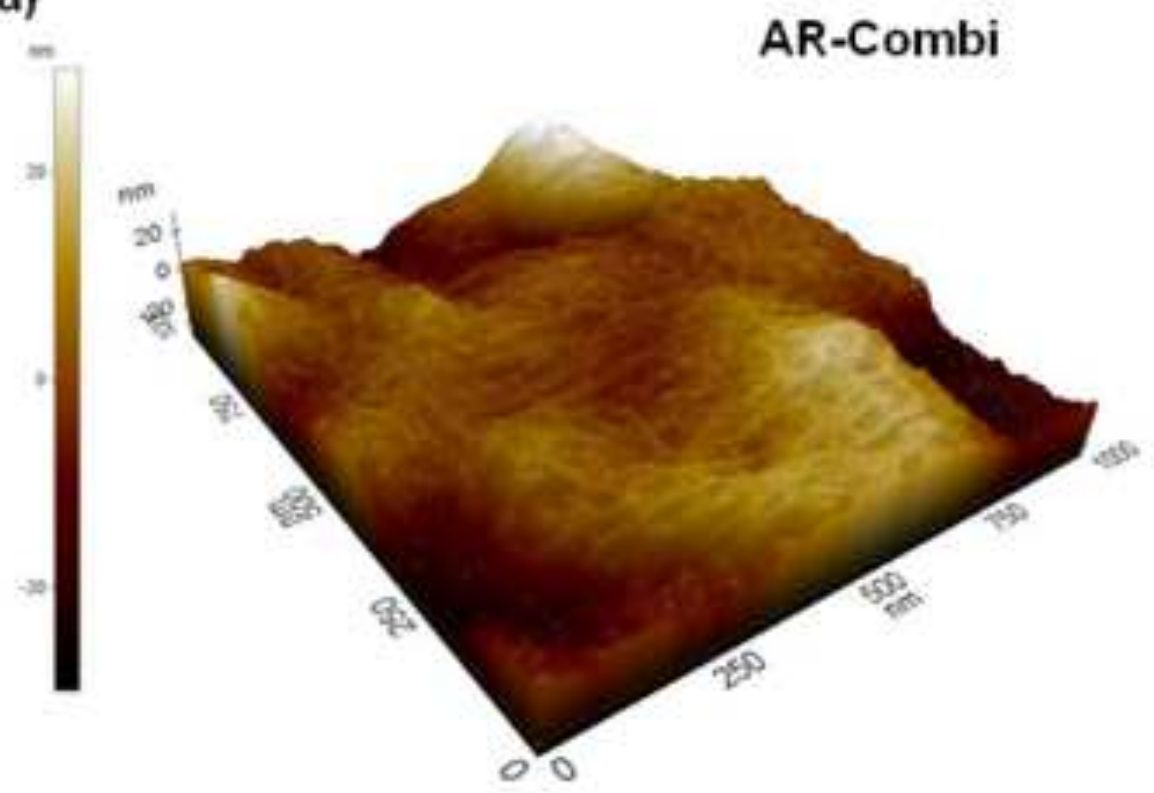

(b)

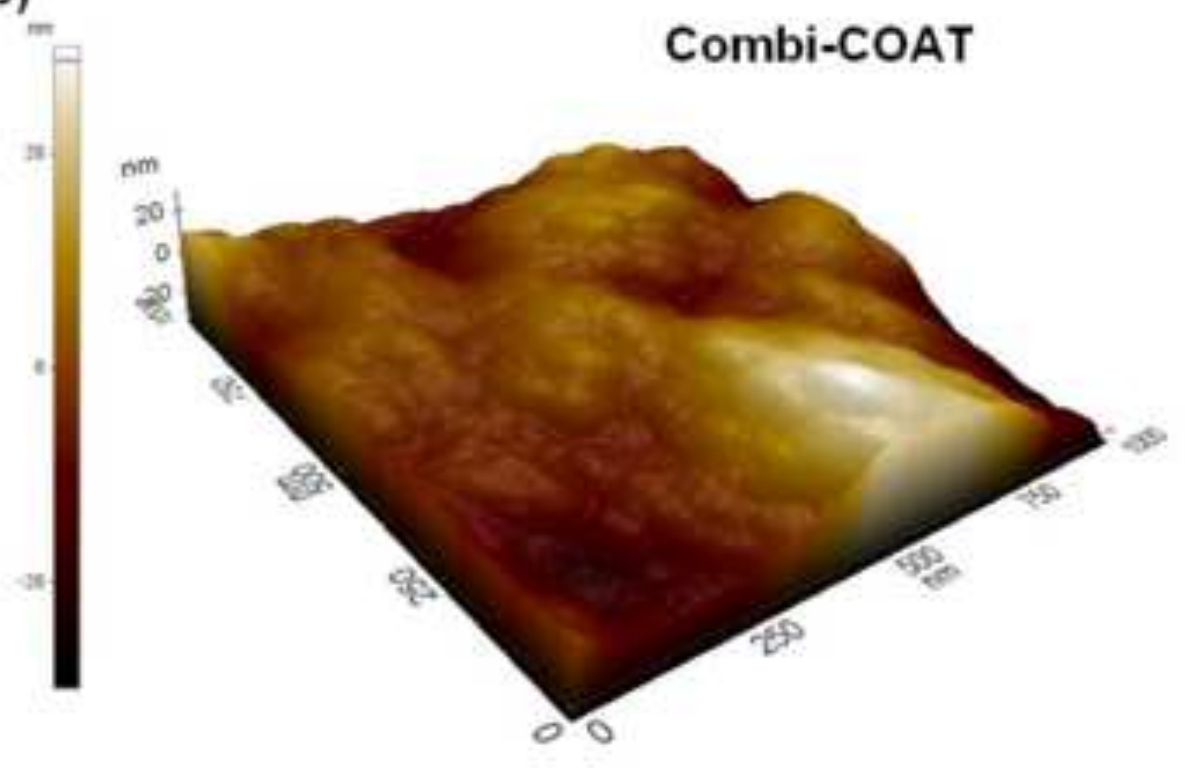


Click here to download high resolution image

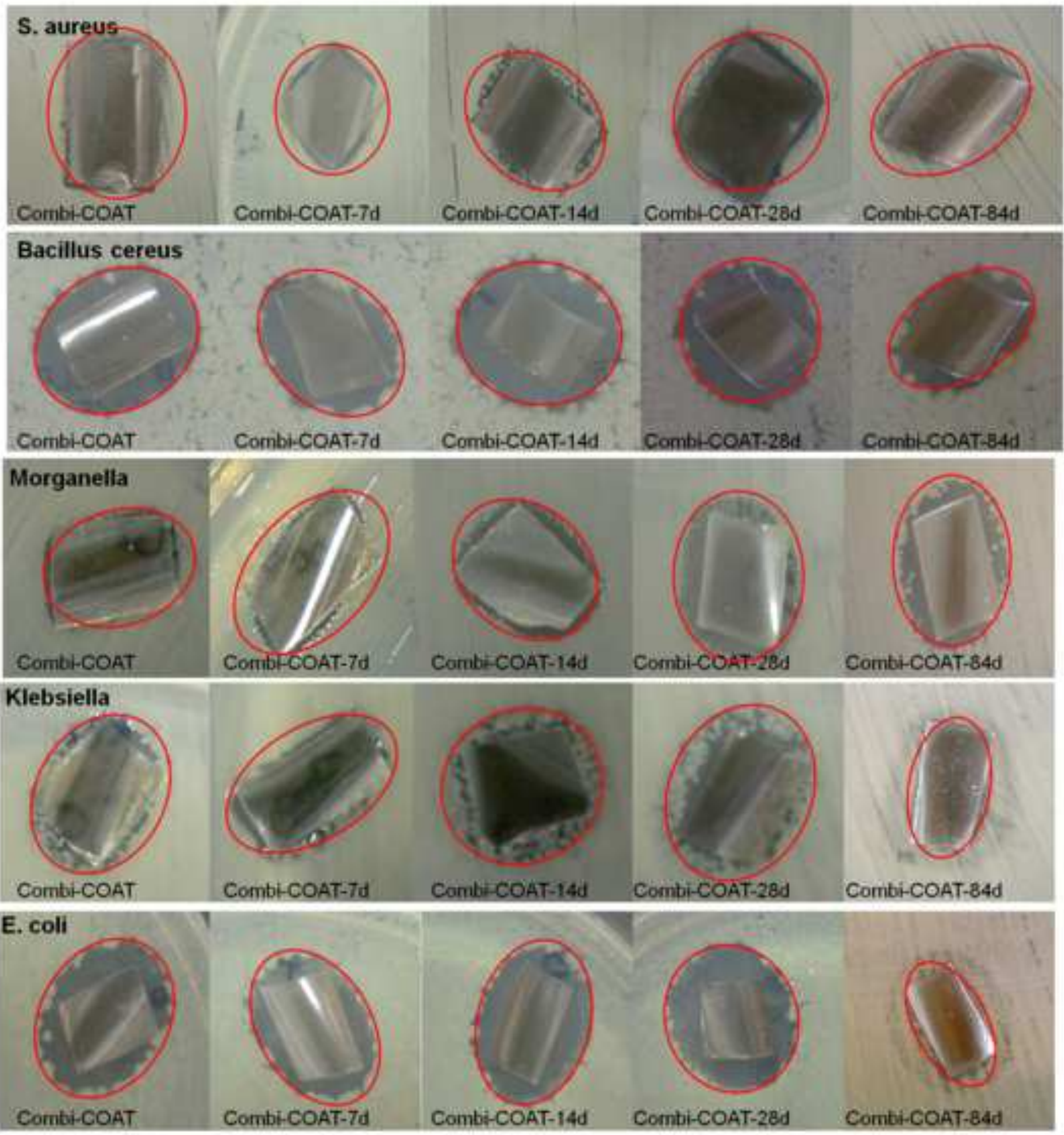



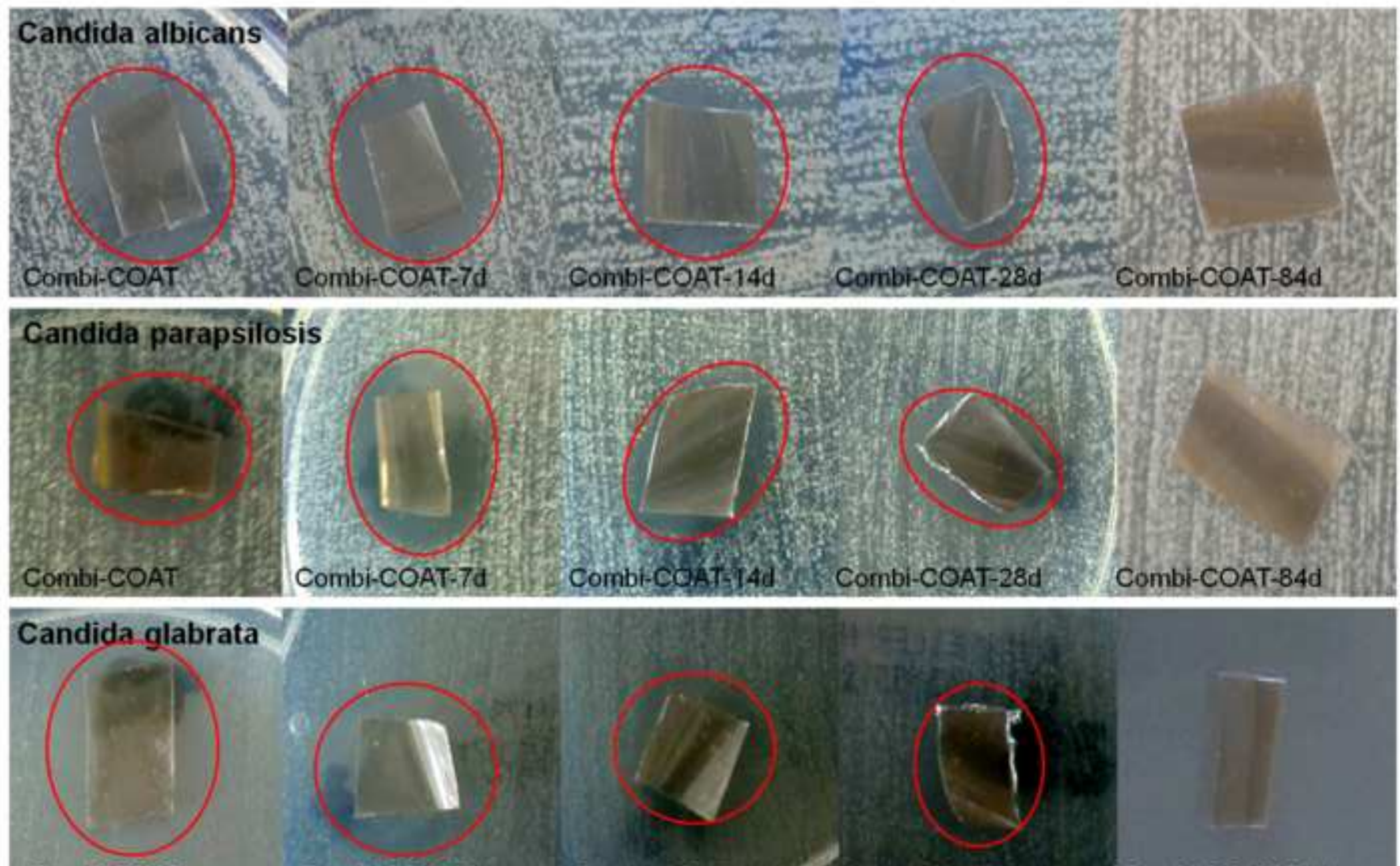

Combi-COAT

Combi-COAT-7d

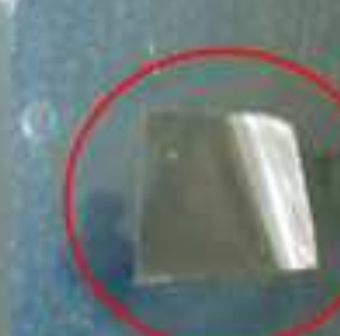

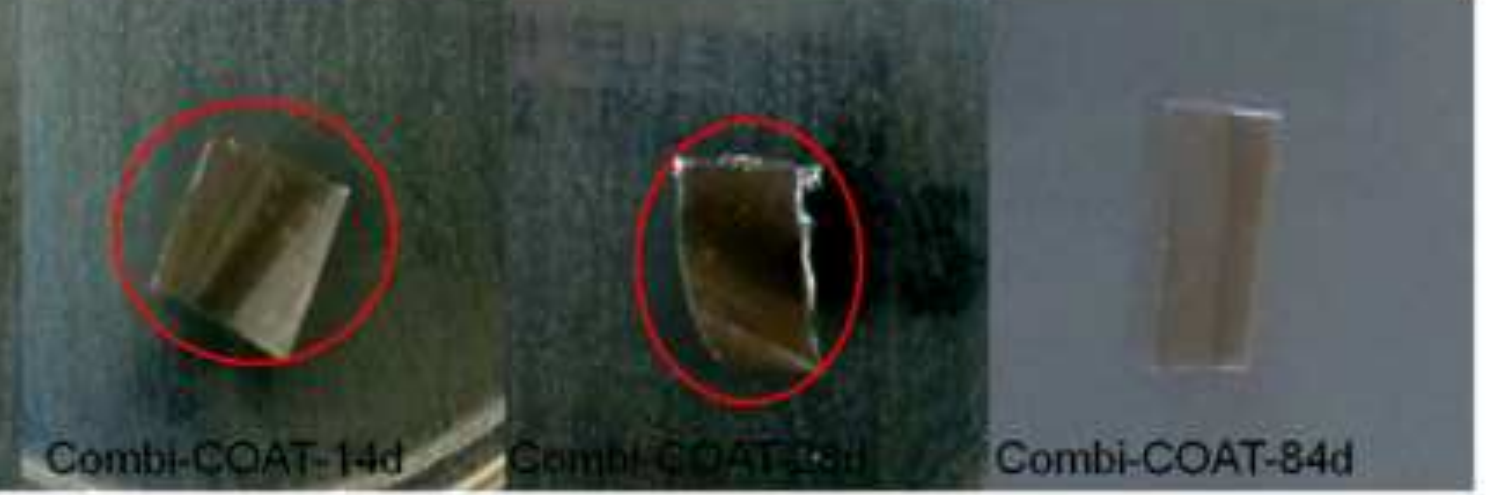




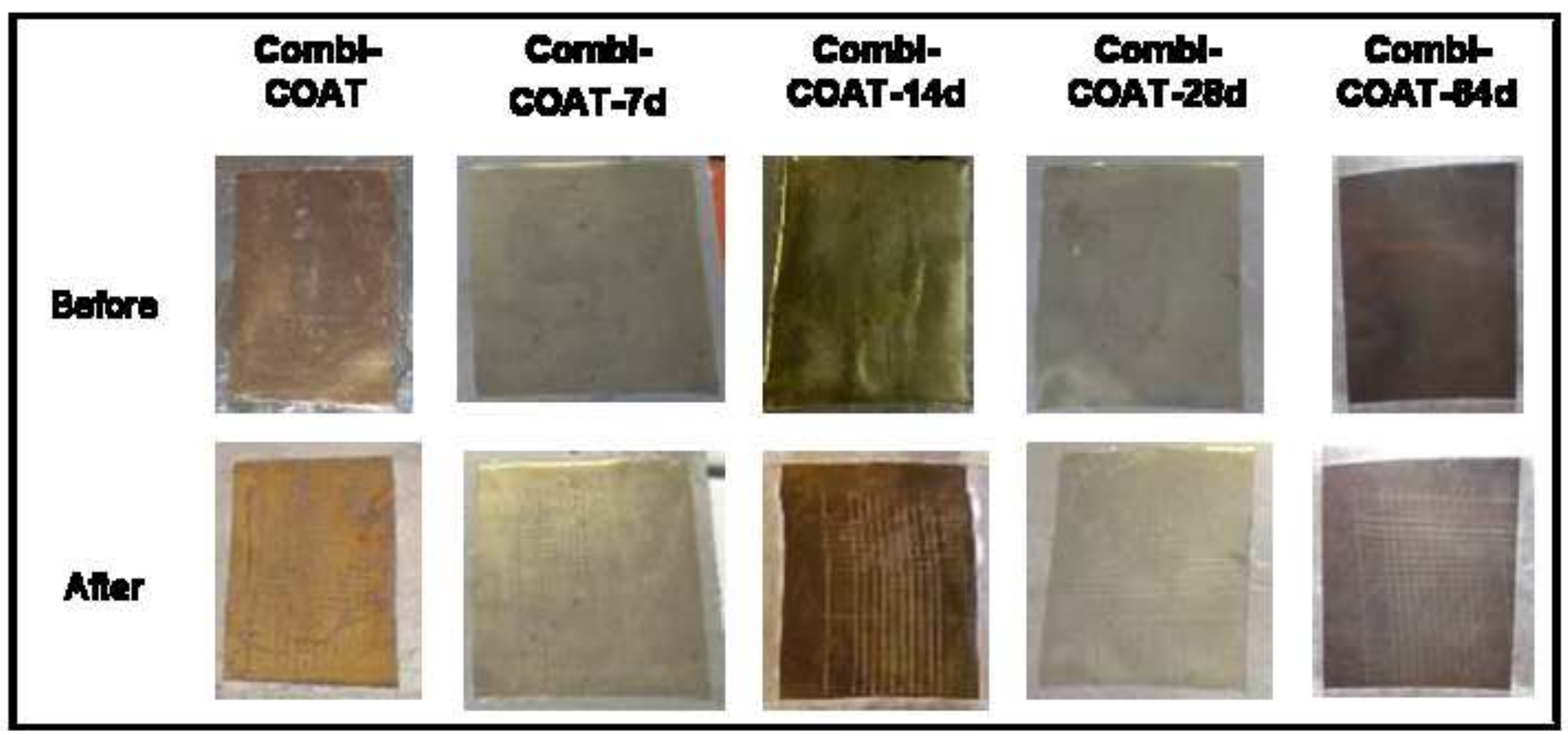
COAT
CombiAT-14d COAT-iAd
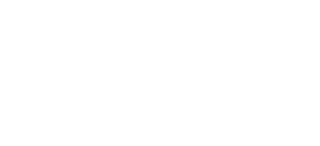
Click here to download high resolution image
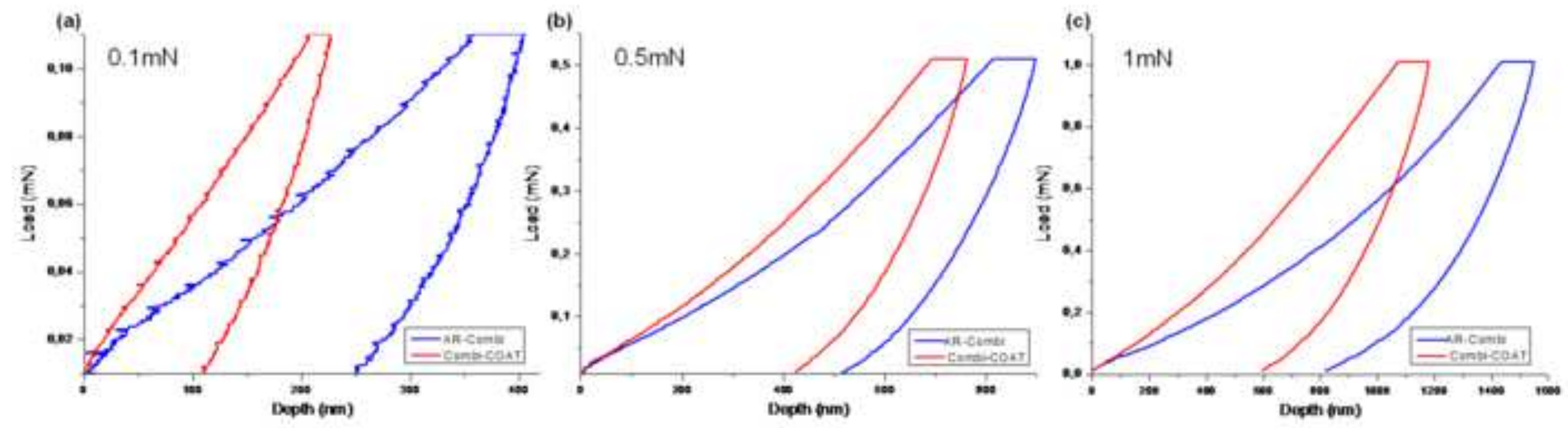
Click here to download high resolution image
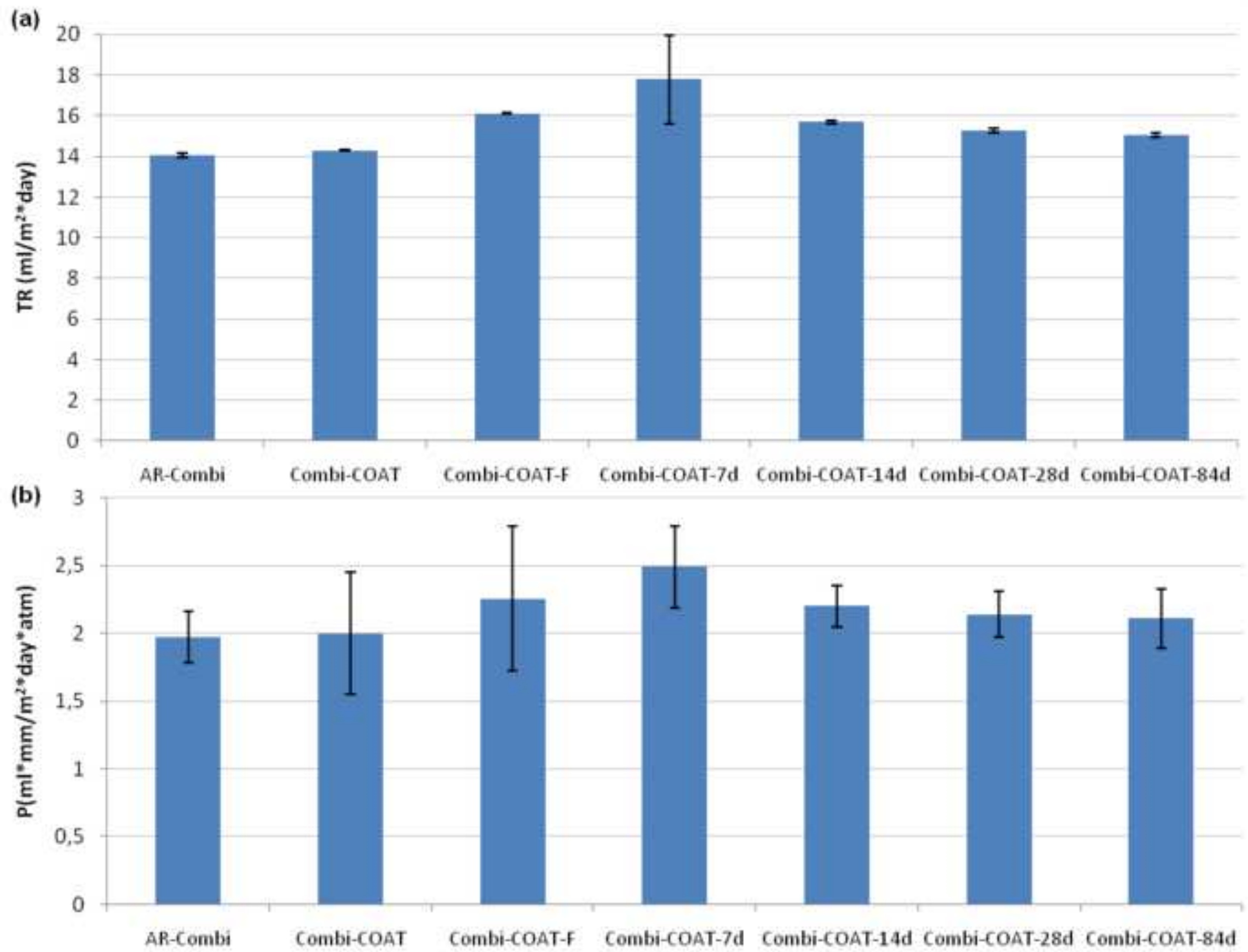